\title{
Considerações peircinanas sobre o gesto na peformance do Grupo UAKTI
}

\author{
Patrícia Furst Santiago (UFMG, Belo Horizonte) \\ furstsantiago@yahoo.com.br \\ André Borges Meyerewicz (UEMG, Belo Horizonte) \\ andborges@uol.com.br
}

\begin{abstract}
Resumo. Este artigo lida com alguns conceitos e significados de gesto em música. A partir de uma definição de alguns dos aspectos que integram o gesto na performance musical e da perspectiva semiótica de Charles Sanders PEIRCE (2000), apresentamos, segundo nossa própria percepção, uma observação qualitativa da gestualidade na performance dos músicos do Grupo UAKTI, buscando compreender seus possíveis significados. Propomos reflexões sobre a função e importância do gesto na performance musical e suas implicações para a pedagogia dos instrumentos.
\end{abstract}

Palavras-chave: gesto, performance musical, semiótica, Grupo UAKTI.

\section{Percian considerations on gesture in the performance of the Grupo UAKTI}

Abstract. This article deals with some concepts and meanings of gesture in music. Based on the definition of some aspects that integrate gesture in musical performance as well as on the semiotic perspective of Charles Sanders PEIRCE (2000), we offer, according to our own perceptions, a qualitative observation of the gestural performances of the musicians that form the Grupo UAKTI in order to understand their possible meanings. We reflect on the function and importance of gesture in musical performance and its implication for the pedagogy of the instruments.

Key Words: gesture, musical performance, semiotics, Grupo UAKTI.

\section{A título de introdução: alguns conceitos e aspectos do gesto}

0 que é gesto em música? Quais são os aspectos do gesto de um músico instrumentista, observáveis na performance musical? 0 que estes gestos representam e comunicam para os espectadores? Que vantagens a observação da performance gestual de um músico traz para a performance e para a pedagogia da performance? Estas são as perguntas que motivaram a elaboração do presente artigo.

Uma definição de dicionário ${ }^{1}$ se refere a gesto como sendo movimento de todos os segmentos do corpo, voluntário ou involuntário, que revela "estado psicológico ou intenção de exprimir ou realizar algo"; o gesto é definido como "aceno, mímica expressão singular, aparência, aspecto, fisionomia maneira de se manifestar; atitude, ação". Porém, à medida que contextualizamos o conceito de gesto, ele se torna um fenômeno complexo, envolvendo aspectos biológicos, psicológicos e sociológicos.
Numa perspectiva sociológica, gesto é algo inteligivel e culturalmente aprendido. Por exemplo, para MAUSS (1974), gestos, postura e movimentos corporais representam mais do que estímulos biológicos; provêem, antes de modelos culturais, de processos de aprendizado que variam de acordo com o contexto sociocultural ao qual o indivíduo pertence. Para MENDES E NÓBREGA (2004, p. 127), gestos são "campos de visibilidade da articulação entre natureza e cultura". Muito embora a produção de gestos seja comum a todos os seres humanos, tais gestos "expressam as singularidades individuais e culturais apresentando linguagens especificas" (MENDES; NÓBREGA，2004, p.127). As autoras ainda acrescentam:

A historicidade do corpo faz que haja modificações e nossos gestos adquirem significados novos mediante as experiências que vêm ocorrendo. E é através desses gestos que somos capazes de expressar muitos desses símbolos e esconder outros, formando, portanto, a linguagem do corpo; o corpo está sempre se reorganizando. E por possuir espacialidade e temporalidade próprias, cada corpo vai adquirindo percepções de acordo com o mundo que lhe é especifico (MENDES; NÓBREGA, 2004, p.129). 
No contexto musical, o conceito de gesto apresenta aspectos diversos. DELALANDE (In: ZAGONEL, 1992, p.22; IAZZETTA, 2000, p.262) indica três níveis do gesto em música: (1) 0 gesto que efetua, necessário para a produção mecânica do som; (2) 0 gesto que acompanha, referente aos movimentos produzidos pelo corpo do instrumentista, mesmo aqueles que não se relacionam diretamente à produção sonora e (3) 0 gesto figurado, relacionado a aspectos metafóricos do gesto musical.

As duas primeiras instâncias indicadas por DELALANDE - o gesto que efetua e o gesto que acompanha - estão certamente relacionadas à natureza cinestética e sensoriomotora da produção sonora. Cinestesia se refere ao "sentido da percepção de movimento, peso, resistência e posição do corpo, provocado por estímulos do próprio organismo".2 DELALANDE afirma que:

0 performer usa corpo e gestos não apenas para produzir sons, mas também para recebê-los. 0 performer percebe com as mãos, boca, respiração, cavidade toráxica e assim por diante. Entre produção e recepção, uma estreita imbricação é estabelecida, bastante comparável àquilo que pode ser observado na infância (DELALANDE, 2003, p.314).

No que diz respeito à terceira instância, o gesto figurado, DELALANDE sugere que uma forma ou contorno sonoro, melódico ou rítmico, pode ter uma natureza sinestésica. Sinestesia se refere à "relação que se verifica espontaneamente (e que varia de acordo com os indivíduos) entre sensações de caráter diverso, mas intimamente ligadas na aparência (por exemplo, determinado ruido ou som pode evocar uma imagem particular; um cheiro pode evocar uma determinada cor, etc.); cruzamento de sensações; associação de palavras ou expressões em que ocorre combinação de sensações diferentes numa só impressão" 3

Para o instrumentista, o simbolismo do movimento é baseado na experiência gestual:

Há uma transição contínua entre a experiência sensoriomotora e o simbolismo; isto pode ser um dos pontos chave para a explicação do significado musical. Em música e, especialmente, na música do mundo ocidental, a representação do movimento tem sido considerada uma das bases do significado (DELELANDE, 2003, p.313).

Quando escutamos um violinista, podemos perceber os movimentos de subida, descida e aceleração do arco; "o primeiro significado relativo ao som de um instrumento é produzido pelo gesto" (DELALANDE, 2003, p.314). Segundo DELALANDE, (2003, p.16) sempre usamos metáforas sinestésicas para descrever sons. Quando ouvimos música, constantemente usamos metáforas, relacionando sons a elementos não sonoros; porém, para vários indivíduos, diferentes formas de escuta e diferentes formas de metaforização podem ser estabelecidas (DELALANDE, 2003, p.16).

Encontramos em LANGER (1953) discussão sobre o aspecto metafórico do gesto, que endossa a existência deste aspecto, referente à terceira instância de Delalande (o gesto figurado). Ela aponta a diferença existente entre uma simples gesticulação comportamental, por exemplo, um aceno de mão, e uma gesticulação artística:

\begin{abstract}
Gesticulação, como parte do nosso comportamento, não é arte. É simplesmente movimento vital... Apenas quando o movimento que foi, inicialmente, um gesto genuino, é executado a partir da imaginação, pode tal gesto se tornar um elemento artístico, uma dança-gestual. Desta forma, ele se torna uma forma simbólica livre, que poderá ser usada para transmitir idéias de emoção, consciência e premonição, ou poderá ser combinada a outros gestos ou incorporada a eles, para expressar uma intenção física e mental (LANGER, 1953, p.175).
\end{abstract}

A função expressiva do gesto é foco de discussão em CAMURRI et al. (2004). Para os autores, o gesto está associado ao domínio afetivo/emocional; gesto pode ser considerado como "expressivo", tendo o propósito de comunicar conteúdos expressivos, relacionados a aspectos tais como sentimentos, afeto e intensidade da experiência emocional (CAMURRI et al., 2004, p.1-2). 0 gesto na performance musical é multimodal por excelência, pois usa os canais auditivo e visual na captação de conteúdos expressivos (CAMURRI et al., 2004, p.3).

ZAGONEL (1992) endossa a visão do gesto como produtor de significados e de expressividade. Para ela, gesto difere de movimento; enquanto movimento se refere a deslocamento ou mudança de posição no espaço em função do tempo, não envolvendo um sentido expressivo, "o gesto tem um objetivo preciso, de produzir ou simbolizar" (ZAGONEL,1992, p.10). A autora distingue dois tipos de gesto, o físico e o mental:

\footnotetext{
0 gesto físico é a ação corporal que, em contato com um objeto, provoca uma reação sonora. Mas o gesto não se limita a uma função técnica de produção de sons, por mais perfeita que seja: ele é, ao contrário, um elemento essencial do fenômeno de expressão musical. [...] 0 gesto mental se produz no pensamento, está sempre presente no músico enquanto compositor ou intérprete. 0 intérprete, a partir da leitura da partitura, imagina o movimento sonoro desejado e associa o gesto físico necessário à emissão desse som. (ZAGONEL, 1992, p.15-17).
}

Segundo ZAGONEL (1992, p.20-1) o gesto de um intérprete participa intimamente na produção do fenômeno sonoro dos instrumentos acústicos; ele é inseparável da percepção tátil e cinestésica do instrumentista e se torna fator determinante na construção da percepção e da musicalidade. Enfim, ZAGONEL vê o gesto como o intermediário entre 0 pensamento musical e seu produto.

Ao enfatizar a importância da conexão existente entre som e imagem, IAZZETTA endossa a natureza multimodal do gesto:

[...] a presença do músico e do instrumento no ato da performance representam algo por si mesmas. A realidade física, biológica e social dessa presença empresta à performance musical, tão imaterial e 
intangível, uma espécie de materialidade. 0 corpo se expressa ao produzir música através do gesto, mapeando o visível e o audivel dentro de uma mesma geografia (IAZZETTA, 1996, p.24).

Também para IAZZETTA, (1996, p.26; 2000, p.260-261) o gesto exerce papel fundamental na produção de sentido musical. Segundo ele, "[...] nós aprendemos a compreender os acontecimentos sonoros com o auxílio dos gestos que produzem ou representam esses sons" (IAZZETTA, 1996, p.26). 0 gesto incorpora múltiplos parâmetros ao mesmo tempo.

Detalhada tipologia de gesto foi proposta por CADOZ E WANDERLEY (2000), a partir da comparação de diferentes definições provindas de diversos domínios, observando suas vantagens e desvantagens, bem como suas limitações e abrangências. Um dos aspectos discutidos pelos autores refere-se à noção de gesto enquanto portador de informação, sendo que a natureza de tal informação não é única nem absoluta, dependendo do objeto em si e do ponto de vista do observador (CADOZ; WANDERLEY, 2000, p.72). Outro aspecto relevante se refere ao gesto em conexão com as posturas físicas assumidas por seu executor. 0 gesto não pode ser considerado como independente da postura que possibilita sua correta realização, uma vez que ele está associado à dinâmica do movimento (CADOZ; WANDERLEY, 2000, p.72), que é realizada pelo corpo como um todo. Assim, gesto e postura coexistem.

CADOZ E WANDERLEY (2000, p.73-4) consideram que a referência ao comportamento corporal tende a ser 0 denominador comum entre a maioria das definições atribuídas ao gesto. Para eles,

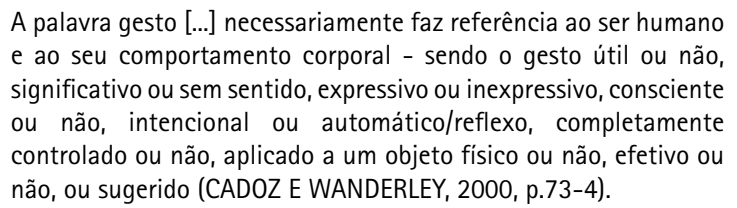

\section{Gesto como ação psicofísica}

As discussões apresentadas acima revelam diferentes perspectivas do gesto na performance musical. Ele é produtor e transmissor do fenômeno sonoro, fundamental para a realização do som no instrumento acústico e para a execução de abordagens técnicas essenciais à realização de determinadas passagens musicais. 0 gesto envolve a percepção tátil e cinestésica do instrumentista, bem como sua atitude postural como um todo. 0 gesto é portador da identidade subjetiva e particular do instrumentista, transmissor de conteúdos expressivos relacionados aos seus sentimentos, afetos e intensidade de sua experiência emocional. 0 gesto é também portador da identidade cultural do instrumentista, envolvendo seus valores, costumes e comportamentos vivenciados socialmente. Tal gesto torna-se transmissor de conteúdos especificamente musicais e também de conteúdos simbólicos e metafóricos, que evocam a cultura através da alusão a símbolos pertencentes ao universo cultural do instrumentista e daquele que o observa.

Importante é enfatizar que, para nós, autores deste artigo, todos estes aspectos da gestualidade de um músico e quaisquer outros que possamos reconhecer como existentes, não atuam de forma isolada. Todos estes atributos do gesto estão integrados na interpretação de uma obra musical. Neste sentido, voltamos nossos olhares para o ser humano que toca um instrumento musical e para os possíveis efeitos de sua gestualidade sobre seus espectadores. Uma vez que o ser humano é um ser psicofísico, holístico, integrado por diversas instâncias - sensoriais, emocionais, mentais, culturais, espirituais, etc., consideramos que a sua gestualidade na performance musical é de natureza psicofísica. 0 gesto passa por seu corpo, visível ao espectador. Mas sendo o sistema humano um sistema psicofísico, não é apenas o corpo que produz o gesto, mas o todo psicofísico de seu ser. Portanto, a realização gestual de um músico instrumentista torna-se uma ação psicofísica, envolvendo um processo cognitivo complexo e integrado, no qual ocorre uma conexão entre as instâncias de vida do ser e os diferentes aspectos que seu gesto pode conter.

Certamente, o estudo de uma obra musical evolui gradualmente, passando por diversas etapas e níveis de aprendizado. Na performance dessa obra, o músico instrumentista pretende apresentar o resultado integrado de seu estudo, fornecendo a seus espectadores uma interpretação unificada. 0 espectador irá, certamente, captar alguns dos significados dessa performance, de forma consciente ou subliminar, parcial ou holistica. Mas em geral, quando a performance é consistente, o espectador reconhece a presença de sentido musical, unidade, coerência.

Enfim, a gestualidade do instrumentista forma um conjunto inseparável do todo de seu sistema psicofísico e do todo de sua performance. Ela pode revelar a busca por um significado que represente sua experiência no momento da performance. Experiência no amplo sentido do termo, com tudo que uma experiência humana pode abarcar sensações cinestésicas, sentimentos, idéias, concepções, intenções, vivências, significados musicais e simbolizações. $\mathrm{Na}$ perspectiva daquele que toca um instrumento, o gesto engendra uma relação entre uma intenção musical, um movimento físico e "algo", um algo artístico; o gesto é "gesto" porque estabelece relações entre eventos, entre instâncias que podem ser percebidas e captadas por nós - relações entre o movimento físico e outra coisa. 0 gesto representa esta "outra coisa", musical ou extra-musical.

Apesar de compreendermos que a gestualidade se articule de forma integrada ao ser que a produz e à sua performance, ao observarmos tal performance, para uma compreensão analítica, faz-se necessário um olhar que segmente vários de seus aspectos. Na multimodalidade, reside nosso ponto de partida para a observação da ação gestual na performance musical. Compreendemos que o conceito de multimodalidade, proposto por CAMURRI at 
al. (2004), pode ser ampliado, pois, além de apontar para a forma multimodal de captar informação musical (auditiva e visual), o conceito pode aludir à superposição de camadas de significados potencialmente contidas no fenômeno musical e aos vários e diferentes aspectos que podem ser foco da observação da gestualidade na performance musical. Assim, apesar de sua natureza holística, o gesto em música abrange vários níveis da percepção humana e atua de forma multimodal, como um canal de comunicação de significados simultâneos, que integram tempo e espaço. Cada gesto específico, realizado por um instrumentista, pode ter sentido e propósito próprios e estimular 0 espectador a captar determinada informação, musical ou não. Cada espectador, por sua vez, pode interagir com esse gesto de forma particular, captando significados que condizem com sua própria condição.

Então, palavras acima citadas indicam uma forma multimodal de ver o gesto em música - percepção tátil e cinestésica, atitude postural, sentimentos, afeto, experiência emocional, metáfora, cultura, significação, informação e comunicação. Tais palavras nos levam a enfatizar as questões de concepção, de função e de significação do gesto e a buscar uma visão que as integre: o gesto como signo. Neste sentido, Charles Sanders Peirce pode nos fornecer, através da perspectiva semiótica, uma compreensão do gesto e suas relações com a performance musical.

\section{Gesto em música a partir da teoria semiótica de Pierce}

Devido à complexidade do pensamento e da arquitetura teórica de Peirce, propomos de uma forma sintética uma abordagem ao conceito de signo. Encontra-se em PEIRCE (2000, pág.36) uma breve definição: "signo é aquilo que, sob certo aspecto ou modo representa algo para alguém. [...] 0 signo representa alguma coisa, seu objeto." De acordo com SANTAELLA (2000, pág.11) seria possivel encontrar mais de 20 formulações ou definições do conceito de signo no decorrer dos oito volumes que formam o Collected Papers, monumental obra de Charles Peirce. No entanto, em uma formulação bastante simplificadora, SANTAELLA (2000, pág.11) fornece uma definição essencial: "Signo é alguma coisa que representa algo para alguém".

De um modo geral, o processo de representação, chamado semiose, sustenta o conceito de signo, por mais amplo ou complexo que seja tal representação. Pode-se, por exemplo, pensar em uma bandeira que representa um país, ou uma cor à qual são atribuídos significados (na cultura ocidental, preto representa luto, ou branco representa paz). Pode-se, então, pensar o gesto em música: movimento corpóreo que possui significados, que representam algo diferente de si próprio (algo musical ou não).

Em Peirce encontramos também uma espécie de estruturação da idéia de signo. Pode-se pensar no signo composto em representamem, objeto e interpretante. Segundo NÖTH (1995, p.66): representamem diz respeito à materialidade perceptível do signo. Ainda de acordo com NÖTH, (1995, p.67) objeto "é o segundo correlato do signo, corresponde ao referente, à coisa (prágma) ou denotatum." Em outras palavras, pode-se pensar no objeto como idéias ou significados representados pelo representamem. Como um exemplo, citamos o signo da cor preto como representação de luto. Por representamem considera-se a cor que veicula a idéia (objeto) de luto. Em NÖTH, (1995, p.71) encontra-se também a noção de interpretante: "0 terceiro correlato do signo que Peirce denominou interpretante é a significação do signo". 4

De um modo geral, consideramos a noção de interpretante associada às noções de representamem e objeto. Voltando ao exemplo anterior, se temos a cor preta (representamem) que veicula a idéia de luto (objeto), consideramos interpretante toda e qualquer razão ou contexto que permitem à cor preta veicular a idéia de luto. 0 interpretante, nesse caso, diz respeito à cultura, aos costumes e histórias que sedimentaram a correlação entre a cor e a idéia, neste caso, a cor preta à idéia de luto. $\mathrm{Na}$ relação entre representamem, objeto e interpretante percebemos o processo de significação, ou seja, a semiose.

Uma vez esclarecido de forma breve o processo semiótico, ainda se faz necessário levar em consideração os graus fenomenológicos que sustentam o processo de semiose proposto por Peirce. Segundo SANTAELLA (2002, p.7) entende-se por fenômeno qualquer coisa que aparece à percepção e à mente. Nesse sentido, a fenomenologia tem por função apresentar as categorias formais e universais dos modos como os fenômenos são apreendidos pela mente. Para Peirce, são três as categorias fenomenológicas: primeiridade, secundidade e terceiridade.

"A primeiridade aparece em tudo que está ligado ao acaso, possibilidade, qualidade, sentimento" (SANTAELLA, 2002, p.7). Neste sentido, fazemos então uma relação entre o conceito triádico de signo e a primeiridade como categoria fenomenológica. A primeiridade faz com que a correlação entre um representamem e seu objeto seja uma mediação subjetiva, pessoal, ligada ao sentimento. Um som musical ou uma seqüência de acordes, considerados como representamem podem evocar um sentimento (objeto) em quem os ouve. A relação entre som e sentimento, neste caso, pode ser uma relação propiciada pelo grau fenomenológico de primeiridade, pois ouvintes diferentes podem ter sentimentos diferentes em relação à sonoridade ou aos acordes.

Segundo SANTAELLA (2002, p.7) "a secundidade está ligada às idéias de dependência, determinação [...] singularidade". No signo, quando a relação entre representamem e objeto se dá de uma forma singular, dependente, determinada, encontramos um signo mediado por um grau fenomenológico de secundidade. Por exemplo: o latido de um cachorro (representamem) percebido por nossos ouvidos nos veicula ao cachorro que produziu o latido. Há uma relação de dependência, determinação, factualidade entre o som e o animal. 
Ainda de acordo com SANTAELLA (2002, p.7) "a terceiridade diz respeito ao crescimento, inteligência". Apesar de tal afirmativa não nos parecer muito clara, Santaella, no decorrer do texto, nos aponta para a terceiridade como o grau fenomenológico que engendra uma relação entre representamem e objeto mediado por uma "lei"; entendemos aqui lei no sentido de convenção ou regra propiciada por um contexto cultural. Uma marcha fúnebre, por exemplo, só pode ser entendida como tal devido a um contexto ou "lei" cultural que engendra um correlato entre a marcha (representamem) e o sentido de morte e ritos funerais.

Uma vez esclarecidos os conceitos de signos e graus fenomenológicos, propomos uma forma de abordar o gesto musical com a intenção de identificar, a partir das categorias fenomenológicas propostas por Peirce, os processos de semiose que correlatam gestos aos seus sentidos ou significados. Se a relação entre o gesto musical e seu significado se der por um correlato baseado na subjetividade, podemos pensar numa relação de primeiridade. Assim, pode-se dizer que o gesto sugere um significado subjetivo, que pode diferir de individuo para indivíduo. Nesse caso, muitos dos gestos realizados por um músico, tais como expressões faciais, movimentos aleatórios e gestos que exprimem sentimentos do intérprete, podem ter significados subjetivos em uma performance musical.

No entanto, no decorrer da perfomance musical, há gestos que dizem respeito a questões da estrutura musical: gestos que revelam fraseados, articulações, dinâmicas. Neste caso, há uma relação de factualidade entre o gesto e seus significados: o gesto representa e indica aspectos da estrutura musical. Pode-se então dizer que tal relação foi mediada em um grau fenomenológico de secundidade. Neste caso, tais gestos "indicam" aspectos da estrutura musical.

Por fim, quando os gestos do intérprete adquirem um significado que se dá por um contexto cultural, tal relação foi mediada por um grau fenomenológico de terceridade. Ocorre aqui, então, um gesto simbólico.

Considerando a teoria de Pierce, podemos realizar a observação da gestualidade na performance musical através de três instâncias, a subjetiva, a indicial e a simbólica, discriminadas abaixo:

(1) Instância subjetiva: Quando a conexão entre o gesto e seu significado se faz por uma relação subjetiva, o gesto se dá em uma relação de primeiridade. Se a relação for de ordem subjetiva, o gesto pode mostrar, dentre outras coisas, características pessoais que são particulares de determinada pessoa. Ex.: movimentos particulares de um instrumentista ao tocar o instrumento. Neste caso, também para o espectador, o gesto é percebido como um processo subjetivo entre movimento e significado.
(2) Instância indicial: Quando a conexão entre o gesto e seu significado se faz por uma relação de factualidade, o gesto se dá por uma relação de secundidade. Neste caso, o gesto se liga a aspectos especificamente musicais: gesto e aspectos musicais se articulam em uma relação física, "de fato". A gestualidade do intérprete revela aspectos da materialidade da obra musical. Ex.: fraseado, estrutura formal, anacruse, ritmo, etc.

(3) Instância simbólica: Quando a conexão entre o gesto e seu significado se faz por uma relação mediada por aspectos culturais, o gesto se dá por uma relação de terceiridade. Neste caso, o gesto comunica significados simbólicos, revelando aspectos que a cultura engendrou. 0 gesto simbólico ultrapassa uma representação de idéias musicais. Ex.: movimentos circulares de corpo no decorrer da performance podem ser lidos como movimentos simbólicos cujos significados dizem respeito a conceitos culturais como significados ligados ao sagrado, idéia de eternidade, mito do eterno retorno, dentre outros.

Sugerimos que as três instâncias ou graus fenomenológicos propostos por Peirce podem abarcar, de uma forma pragmática e sintética, muitos dos fatores que têm formado os diversos conceitos de gesto em música e podem nos ajudar a ver a situação do gesto na performance sob o ponto de vista do instrumentista e de seu espectador. Tais instâncias são inclusivas, ou seja, a gestualidade de um músico/instrumentista será caracterizada pela integração destes três aspectos, formando sua imagem psicofísica ou identidade gestual global. Assim, no decorrer deste artigo, faremos uma observação dos gestos e de seus significados na perfomance gestual dos músicos do Grupo UAKTI a partir de tais instâncias. Tentaremos perceber em performances de peças musicais específicas do UAKTI gestos que sugerem significados subjetivos (instância subjetiva, grau fenomenológico de primeiridade); gestos que indicam significados ligados à estrutura musical (instância indicial, grau fenomenológico de secundidade) e gestos que engendram significados simbólicos (instância simbólica, grau fenomenológico de terceiridade).

\section{Observação e análise da performance gestual do UAKTI}

Apresentamos aqui o processo de observação das performances dos percussionistas Décio Ramos e Paulo Santos, na peça "Trilobita" e do flautista Artur Andrés na peça "Krishna I", que estão disponiveis no DVD intitulado UAKTI. ${ }^{5}$ Enfatizamos que o processo de observação aqui empreendido leva em consideração os conceitos de Peirce e são conduzidos de acordo com as concepções particulares dos autores do presente artigo. Outros observadores, bem como os próprios músicos, certamente poderiam oferecer interpretações diferentes das aqui apresentadas. 
As perguntas que motivaram nossa observação e que procuramos responder ao longo desta seção são: (1) Que tipos de gestos nós observamos nas performances dos músicos do UAKTI, nas referidas peças? (2) Quais são as instâncias desses gestos que nós poderíamos observar? (3) 0 que estes gestos representam e comunicam para nós?

A trajetória metodológica qualitativa, adotada para a observação das performances, envolveu duas etapas iniciais. Primeiramente, assistimos as performances das peças "Trilobita" e "Krishna I" buscando ter uma visão geral da gestualidade apresentada pelos músicos. A seguir, revimos as performances sucessivamente, para obtermos uma descrição da gestualidade de cada um dos três músicos. Inserimos os gestos observados dentro das categorias específicas baseadas na teoria semiótica de Peirce (subjetiva, indicial e simbólica), criando unidades significativas a partir das quais pudéssemos explicar sua natureza e os significados que tais gestos tiveram para nós.

É importante enfatizar que nosso foco de observação foi a gestualidade dos músicos. Muitas vezes, mudanças da gestualidade pareceram acompanhar mudanças do aspecto formal das peças, mas isto não foi uma regra. Portanto, nossa leitura aponta para grandes momentos gestuais que podem estar relacionados, ou não, à estrutura das peças. Para facilitar o entendimento das observações que apresentaremos a seguir, optamos por designar os músicos apenas pelo seu primeiro nome: Décio, Paulo e Artur. 0 leitor poderá compreender melhor os detalhes de nossa observação se tiver acesso à gravação das performances em DVD. ${ }^{6}$

\subsection{Gestualidade dos percussionistas Décio Ramos e Paulo Santos em "Trilobita"}

\section{Momento gestual 1: gestos de reconhecimento do território sonoro}

Este primeiro momento corresponde à introdução da peça. Os músicos percutem o instrumento "Trilobita", que consiste num grupo de tambores formado por tubos de PVC. Os tubos são cobertos por pele de cabra e se encaixam numa mesa de compensado de madeira. ${ }^{7}$ Gestos realizados por Décio e Paulo, tais como percutir diferentes lugares do instrumento, simulações de percussões no ar, batidos no microfone instalado acima do instrumento, batidas na própria cabeça, sugerem uma espécie de reconhecimento do território sonoro, propondo um caráter de experimentação e uma atitude lúdica. Foram notados sorrisos e expressões faciais de ambos os instrumentistas - Décio e Paulo - que a nós, autores deste artigo, sugerem cumplicidade existente entre eles, e também prazer e envolvimento.

Evidentemente, além dos gestos lidos numa instância subjetiva, os músicos realizam gestos relacionados à produção sonora no instrumento e expressão de estruturas sonoras, que podem ser lidos na instância indicial, pois tais movimentos indicam conexões com estruturas musicais.

Notamos, no entanto, que Décio realiza um gesto que aponta para um significado que envolve um grau cultural simbólico (instância simbólica): o gesto em que ele pega a mão de Paulo e a coloca sobre o instrumento, como que para conduzi-lo. Na cultura ocidental, o gesto de pegar na mão do outro, possui, simbolicamente, vários significados. Porém, interpretamos tal gesto realizado por Décio como referente à idéia de conduzir, levar, orientar seu parceiro de performance.

\section{Momento gestual 2: alternâncias e simultaneidades sonoras}

Depois de estabelecido o caráter lúdico no momento gestual 1, a peça apresenta alternâncias e simultaneidades sonoras que sugerem um diálogo entre os músicos. Compreendemos que, em música, este referido diálogo pode abarcar a ocorrência de estruturas sonoras que podem se apresentar de forma alternada ou simultânea. Tal diálogo se inicia com ataques alternados no instrumento por parte dos músicos. Gradualmente eles realizam ataques simultâneos nos instrumentos. Neste momento, para os nós, autores, não há ênfase numa gestualidade que propicie significações num modo subjetivo (instância subjetiva). Aparentemente, também não há gestualidade dos músicos que aponte para significados simbólicos (instância simbólica). Há, então, uma prevalência de gestualidade dos músicos associada à produção sonora e à estrutura musical, ou seja, tais gestos revelam aspectos da estrutura musical - gestos que indiciam estruturas musicais (instância indicial).

\section{Momento gestual 3: ostinatos e solos}

Neste momento, não notamos gestualidades dos músicos que sugerem uma ênfase na instância subjetiva. 0 caráter lúdico de diálogo permanece. Inicia-se um momento no qual um ostinato rítmico serve de base para um solo. Primeiramente Décio realiza um ostinato e Paulo um solo. Depois, vice-versa. No final deste momento, há um acelerando que culmina na próxima seção da peça. Para nós, parece não haver gestualidade dos músicos que aponte para um significado simbólico. Neste momento gestual, assim como no anterior, notamos uma prevalência de gestualidade dos músicos associada à produção musical, portanto gestos indicadores de estruturas musicais (instância indicial).

\section{Momento gestual 4: simultaneidade}

Aqui não notamos uma gestualidade dos músicos que sugere uma ênfase nas instâncias subjetiva e simbólica. 0 caráter lúdico de diálogo permanece. A partir do acelerando da seção anterior, os músicos chegam a um momento musical intenso: eles tocam simultaneamente ostinatos ritmicos, num crescendo e acelerando. Neste momento, nota-se algo interessante. Sílabas vocais são realizadas pelos músicos e parecem se relacionar às células rítmicas 
executadas no instrumento, reforçando-as e levando a música a um maior adensamento sonoro. Assim, notamos uma prevalência de gestualidade associada à produção musical, portanto indicial.

\subsection{Gestualidade do flautista Artur Andrés em "Krishna I"}

\section{Momento gestual 1: gestos na introdução da peça}

Os três músicos executam esta peça, porém o solo é realizado por Artur, na flauta transversal. Décio e Paulo tocam um instrumento chamado "Torre". ${ }^{8} 0$ primeiro momento gestual corresponde à introdução da peça. Décio inicia o movimento de girar o instrumento "Torre", no silêncio. A seguir, Paulo fere as cordas do instrumento com um sistema formado por dois arcos. Os gestos executados por Décio e Paulo funcionam numa instância indicial, pois estão relacionados à produção sonora e à estrutura musical: uma sonoridade em contínua modulação nos parâmetros altura, intensidade e tempo (ritmo) é instalada por Décio e Paulo na "Torre" e permanece como base para o solo de flauta transversal que será executado por Artur. Para nós, neste momento gestual, os gestos realizados pelos músicos estão em função das estruturas musicais (instância indicial).

\section{Momento gestual 2: gestos iniciais do flautista}

Artur entra em cena tocando a flauta transversal, caminhando lentamente. Para nós, numa instância subjetiva, este caminhar sugere leveza, além de favorecer a instauração de um caráter musical de introspecção. A seguir, numa instância indicial, Artur executa gestos de balanço do corpo e movimentos de cabeça que indicam estruturas musicais, tais como anacruses e desfechos de frases musicais.

\section{Momento gestual 3: gestos circulares}

Artur inicia um lento movimento circular, girando o corpo. Este movimento vai se acelerando, enquanto a melodia realizada na flauta continua. Nesse momento, o gesto de girar se integra à melodia e se liga a uma interpretação do tempo como uma vivência circular. Isto implica que, neste caso, o gesto tem um significado simbólico, pois em nossa cultura, movimentos circulares dessa natureza remetem a simbologias tais como, vivência da totalidade do self, integração do self com tudo que o rodeia, percepção circular de vida, mito do eterno retorno, eternidade, misticismo. 0 gesto circular diminui gradualmente até o fim da peça. No último momento, Artur realiza um último gesto que nos remete novamente para a instância simbólica: ele aponta a flauta para cima, o que poderia ser interpretado como uma simbologia de transcendência.

\section{Comentários finais}

Neste artigo, focamos o conceito de gesto no contexto da performance musical. Compreendemos que a gestualidade de um músico instrumentista pode revelar inúmeros significados associados à sua experiência no momento da performance, envolvendo todo o seu organismo psicofísico. 0 gesto de um músico também expressa suas idéias e concepções musicais e, muitas vezes, idéias extramusicais, através do uso de símbolos e metáforas. Toda a gestualidade apresentada por um músico instrumentista na peformance se abre para inúmeras leituras, de acordo com diferentes observadores. 0 que nos propusemos no artigo foi oferecer nossa própria reflexão sobre o conceito de gesto embasados na perspectiva semiótica de Charles Sanders Peirce. A partir de tal perspectiva, empreendemos uma observação qualitativa da performance gestual dos músicos do Grupo UAKTI e inferimos potenciais significados de tal gestualidade.

0 relacionamento estabelecido entre os percussionistas Décio Ramos e Paulo Santos na peça "Trilobita" nos aponta para um diálogo musical que se estrutura em torno de perguntas e respostas. Este diálogo é claramente explicitado pelos gestos de ambos os músicos. $\mathrm{Na}$ performance, ocorre intensa sincronicidade rítmica sendo a peça executada com grande apuro técnico e musical. Igualmente, na peça "Krishna I", Artur Andrés nos mostra o gesto como resultado de uma integração dos diversos aspectos que compõem sua interpretação: o psicofísico, o musical e até o simbólico. A gestualidade dos três músicos do UAKTI nos revela um envolvimento holístico com o ato de tocar e de fazer música.

Enfim, a gestualidade dos músicos do UAKTI forma um conjunto inseparável do todo de seu sistema psicofísico e do todo de sua performance, consistindo numa ação psiofísica. Por outro lado, sua performance gestual evidencia a natureza multimodal do gesto em música, através dos diversos significados potencialmente suscitados ao espectador significados que nos foram revelados a partir da adoção das três instâncias semióticas de Peirce, a subjetiva, a indicial e a simbólica. Porém, é conveniente esclarecer que nossa leitura da gestualidade dos músicos do UAKTI revela apenas nossa percepção sobre as tendências gestuais destes músicos em momentos específicos de suas performances. Outros observadores, assim como os próprios músicos, poderiam oferecer interpretações bem diversas daquelas que oferecemos aqui. Por outro lado, também compreendemos que as instâncias subjetiva e indicial são inerentes às performances musicais de qualquer intérprete. Já a instância simbólica, que suscita significados extra-musicais, nem sempre estará presente em uma interpretação.

Agora, nos perguntamos: Quais são as aplicações práticas da observação da gestualidade de músicos instrumentistas, tais como a que empreendemos aqui, para a performance e para a pedagogia da performance musical? Para a performance musical, fica destacado que a performance ao vivo envolve uma função multimodal; o gesto é fator preponderante nesta função. Quando o processo de expressão e significação musical é bem sinalizado em termos de gesto, poderá haver otimização da comunicação entre músico e espectador. 0 movimento físico na performance tem um conteúdo de linguagem que pode veicular informações musicais e extra-musicais. 
$\mathrm{Na}$ instância indicial, o gesto se liga factualmente a aspectos da estrutura musical. Por ser assim, o gesto pode revelar aspectos da estrutura de uma obra musical não tão perceptíveis auditivamente, ou enfatizar tais estruturas, que se tornam mais "visíveis", mais facilmente apreensíveis pelo espectador. Além do mais, como explica DELALANDE (2003, p.315), a coerência gestual está ligada à expressão. Um músico/instrumentista poderia, por exemplo, realizar movimentos para indicar anacruses de frases musicais, articulações rítmicas, dinâmicas. Músicos cameristas poderiam realizar gestos de regência com 0 intuito de comunicação mútua, etc.

Por outro lado, pode haver aspectos extra-musicais numa performance, tornando-a, ao mesmo tempo, música e símbolo. Neste caso, o gesto pode propor metáforas que o som não pode revelar, tais como a metáfora do círculo identificado por nós na performance do flautista Artur Andrés na peça "Krishna I". Ademais, frequentemente há elementos subjetivos na performance de qualquer músico instrumentista, que apontam para suas características individuais no ato de tocar, tais como expressões faciais que sugerem sentimentos e sensações. Em suma, o músico instrumentista revela suas concepções sonoras e vivências psicofísicas, relativas à performance, através de movimentos expressos pelo corpo: o conjunto destes movimentos torna-se ações gestuais psicofísicas, sejam elas subjetivas, indiciais ou simbólicas, formando sua identidade gestual global. Mesmo na audição de uma gravação, tal identidade poderia ser revelada ao ouvinte, como esclarece DELALANDE (2003, p.315): "ao ouvir sons fortes ou suaves produzidos por um músico instrumentista, somo capazes de inferir o gesto que foi adotado para tal realização porque, através da nossa educação sensoriomotora, nos tornamos aptos a traduzir um som em gesto".

No que diz respeito à pedagogia da performance musical, alguns dos aspectos do gesto discutidos aqui se mostram especialmente relevantes. A possibilidade do gesto ser tratado como sugestão de conteúdos extra-musicais (em instância subjetiva), é importante. Muito se tem usado tal potencialidade, especialmente no ensino de instrumentos para iniciantes, notadamente no ensino do piano e também na educação musical. Por exemplo, o uso de sons instrumentais que sugerem conteúdos semânticos (sons que criam cenários, tais como chuva, movimentos de animais, sons da cidade). A natureza multimodal do gesto torna-se, novamente, fundamental.

Por ter uma repercussão audiovisual, o gesto pode indicar para um professor de instrumento a qualidade de uso do corpo de seus alunos - os níveis de tensão e de movimentação excessiva presentes em sua performance. Alem disso, determinados gestos resultam de movimentos produzidos para se alcançar determinados resultados sonoros, desejáveis para a execução de certas passagens musicais específicas. Assim, o gesto é parte integrante da técnica musical, compreendendo que um conceito abrangente de técnica envolve os aspectos motores es aspectos musicais de uma performance. Este ponto nos leva a outros dois, propostos por ZAGONEL (1992, p.201): o gesto como intermediário entre o pensamento musical e seu produto e o gesto como fator determinante na construção da percepção e da musicalidade. Na pedagogia da performance, muito se poderia fazer para unificar o desenvolvimento técnico de um aluno em conexão com os aspectos musicais a serem trabalhados, uma vez que há uma correspondência entre o processo motor, a compreensão musical e o efeito sonoro a ser alcançado, aliados às questões de linguagem e estilo musical. 0 processo de ensino e aprendizado de um instrumento musical deveria integrar estes aspectos de forma mais holística possivel e talvez, através do estudo do gesto na obra musical, esta integração seja em muito favorecida. A afirmação de CADOZ E WANDERLEY (2000, p.72) endossa este ponto de vista: "O comportamento gestual gera um todo complexo, um sistema composto por múltiplas funções que são articuladas e combinados entre si. Uma separação ou divisão excessiva de seus componentes poderia levar à perda de sua substância".

Dentro da visão holística que propomos neste artigo, compreendemos que não existe na performance musical algo que possamos considerar como apenas "produção sonora", pois toda produção do som está ligada factualmente a gestos que têm algum tipo de significado. Uma simples produção sonora talvez represente apenas uma ação mecânica; porém, mesmo uma simples ação mecânica deveria existir factualmente em função da produção de uma idéia sonora. No ato de fazer música num instrumento, entendemos que não é produtivo pensar num movimento físico que "produza" um som sem que haja uma conexão deste movimento com estruturas musicais ou com outros significados.

0 que compreendemos através da observação empreendida neste artigo é que, como espectadores, muitas vezes precisamos segmentar os diversos aspectos da performance gestual de um músico para melhor apreciá-la e compreendê-la. No entanto, o que mais nos fascina é a natureza holística do gesto, o que fica bem exemplificado na performance gestual dos músicos do UAKTI, mas que certamente poderia ser observado em performances de um número incontável de músicos instrumentistas. Enfim, acreditamos que músicos e professores de música se beneficiariam ao considerar que o gesto é parte integrante do estudo da obra musical e do instrumento. A busca por uma gestualidade coerente com a intenção musical poderá proporcionar um melhor desenvolvimento da compreensão musical e das habilidades técnicas desde o início do aprendizado, levando músicos instrumentista a alcançar níveis mais apurados de performance musical. 


\section{Referências}

CAD0Z, Claude; WANDERLEY, Marcelo M. Gesture - Music. In: Trends in General Control of Music. M.M. Wanderley e M. Battier (Eds.), Ircam - Centre Pompidou, 2000, p. 71-94.

http://www.idmil.org/_media/wiki/cadoz_wanderley_trends.pdf?id=publicationsftcache=cache.

CAMURRI, Antonio; MAZZARINO, Bárbara; RICCHETTI, Matteo; TIMMERS, Renee; VOLPE, Gualtiero. Multimodal analysis of expressive gesture in music and dance performances. InfoMus Lab. DIST - University of Genova, 2004, p. 1-20.

http://www.nici.kun.nl/mmm/papers/Camurrietal04.pdf

DELALANDE, François. Sense and intersensoriality. In: Leonardo, Vol. 36, N. 4, 2003, p. 313-316.

http://www.leonardo.info/isast/journal/toc364.html

IAZZETTA, Fernando Henrique de Oliveira. Música Practica In: Sons de Silício - Corpos e máquinas fazendo música. Tese de Doutorado. Pontifícia Universidade Católica de São Paulo - PUC, São Paulo, p. 16-40, 1996.

http://www.eca.usp.br/prof/iazzetta/papers/tese.htm

IAZZETTA, Fernando Henrique de Oliveira. Meaning in musical gesture. In: Trends in General Control of Music. M.M.

Wanderley e M. Battier (Eds.) Ircam - Centre Pompidou, 2000, p. 259-268.

LANGER, Suzanne K. Feeling and Form. Routledge \&t Kegan Paul, 1953.

MAUSS, Marcel. As técnicas corporais. In: Sociologia e Antropologia, Vol. II. São Paulo: EDUSP,1974.

MENDES, Maria Isabel Brandão de Souza e; NÓBREGA, Terezinha Petrucia da. Corpo, natureza e cultura: contribuições para a educação. Revista Brasileira de Educação. Set-out-nov-dez, N. 27, p. 2004, p. 125-137.

http://www.scielo.br/pdf/rbedu/n27/n27a08.pdf

NÖTH, Winfried. Panorama da Semiótica - de Platão a Peirce. São Paulo: Annablume, 1995.

PEIRCE, Charles Sanders. Semiótica. Sâo Paulo: Perspectiva, 2000.

RIBEIRO, Artur Andrés. UAKTI - um estudo sobre a construção de novos instrumentos musicais acústicos. Editora C/ARTE, 2004.

SANTAELLA, Lúcia. A Teoria Geral dos Signos. São Paulo: Pioneira, 2000.

SANTAELLA, Lúcia. Semiótica Aplicada. São Paulo: Pioreira Thompson Learning, 2002.

ZAGONEL, Bernadete. 0 que é gesto musical. São Paulo: Editora Brasiliense, 1992.

DVD

UAKTI. DVD gravado em 17 de setembro de 2006 no Teatro do Palácio das Artes, Belo Horizonte.

\section{Notas}

1 Dicionário Eletrônico Houaiss da Língua Portuguesa, 1.0.

2 Dicionário Eletrônico Houaiss da Língua Portuguesa, 1.0.

3 Dicionário Eletrônico Houaiss da Lingua Portuguesa, 1.0.

4 Algumas vezes Peirce também fala de significance, significado ou interpretação do signo.

5 UAKTI. DVD gravado em 17 de setembro de 2006 no Teatro do Palácio das Artes, Belo Horizonte.

6 Para se familiarizar com a música do UAKTI, o leitor poderá, alternativamente, consultar o site do grupo, onde alguns vídeos e gravações estão disponiveis: http://www.berm.co.nz/cgi-bin/video/browse.cgi?t=uakti

7 Para obter maiores detalhes sobre o instrumento "Trilobita", o leitor poderá consultar RIBEIRO, 2004.

8 Para obter maiores detalhes sobre o instrumento "Torre", o leitor poderá consultar RIBEIRO, 2004.

Patrícia Furst Santiago é professora visitante na Escola de Música da UFMG (PROCOD/CAPES), onde conduz pesquisa sobre a Técnica Alexander e performance musical. Obteve o Doutorado em Educação Musical e o Mestrado em Educação Musical no Instituto de Educação da Universidade de Londres; o Bacharelado em Piano e a Especialização em Educação Musical na Escola de Música da UFMG. Formou-se como professora da Técnica Alexander no Constructive Teaching Centre em Londres.

André Borges Meyerewicz é professor da Universidade do Estado de Minas Gerais - UEMG, Escola de Design, onde ministra a disciplina "Semiótica". É também professor do curso de Design Gráfico do UNI-BH. Obteve o Mestrado em Letras (na linha de Literatura e outros Sistemas Semióticos) na Faculdade de Letras da UFMG. 